\title{
Pengaruh Customer Relationship Marketing Terhadap Customer Loyalty Melalui Customer Value Pada Bank Jatim Di Jember
}

\section{(The Influence Of Customer Relationship Marketing to Customer Loyalty Through Customer Value in Bank Jatim Jember)}

\author{
Rizal Syahrial Riadi, Diah Yulisetiarini ${ }^{1}$, Gusti Ayu Wulandari \\ Jurusan Manajemen, Fakultas Ekonomi dan Bisnis, Universitas Jember (UNEJ) \\ Jln. Kalimantan 37, Jember 68121 \\ E-mail: diah.yulisetiarini80@gmail.com
}

\begin{abstract}
Abstrak
Penelitian ini menganalisis pengaruh Customer Relationship Marketing, Customer Value terhadap Customer Loyalty pada Bank Jatim Jember. Artikel ini menggunakan pendekatan explanatory research, populasi yang digunakan adalah seluruh nasabah yang berada Bank Jatim Jember dan pengambilan sampel menggunakan rumus ferdinand dengan diperoleh 110 responden. Metode analisis yang digunakan dalam penelitian ini menggunakan analisis jalur. Hasil penelitian ini adalah Customer Relationship Marketing berpengaruh signifikan terhadap Customer Value, Customer Relationship Marketing berpengaruh signifikan terhadap Customer Loyalty, Customer Value berpengaruh signifikan terhadap Customer Loyalty.
\end{abstract}

Kata Kunci: Hubungan Pelanggan Pemasaran, Nilai Nasabah, Loyalitas Nasabah, Analisis Jalur

Abstract

This research is aimed to analyse the influence of customer relationship marketing and customer value to customer loyalty in Bank Jatim Jember. This reserach using explanatory research aproach, the population are those customers who of bank jatim jember with obtained 110 respondents as sample using ferdinand formulas. The analyse method in this research using path analyse .The result of this research is customer relationship marketing significantly influenced customer value, customer relationship marketing significantly influenced customer loyalty, customer value significantly influenced customer loyalty.

Keywords: Customer Relationship Marketing, Customer Value, Customer Loyalty, Path Analisys

\section{Pendahuluan}

Perkembangan perekonomian dalam negeri ini telah semakin cepat berkembang maka dari itu bisnis perbankan menjadi salah satu bisnis di bidang jasa yang telah berkembang cepat. Maraknya kejahatan maka dari itu para nasabah bank telah berfikir untuk menyimpan aset berharga yang mereka miliki di tempat yang aman salah satunya pada bank. Upaya perusahaan untuk dapat hidup dan berkembang dengan menarik minat pelanggan dan mempertahankan pelanggan yang sudah ada agar tidak berpindah ke perusahaan lain, tujuan akan tercapai jika sebuah perusahaan melakukan proses pemasaran.

Pemasaran merupakan salah satu kegiatan pokok yang dilakukan oleh perusahaan untuk mempertahankan kelangsungan hidup usahannya dengan menggunakan paradigma baru, tidak hanya menciptakan transaksi, tetapi perusahaan juga harus menjalin hubungan dengan pelanggan (Relationship Marketing) dalam waktu yang panjang (Kotler dan Amstrong, 2003: 302).Perusahaan perbankan menjadi perusahaan jasa yang memberikan pelayanan kepada pelanggan atau nasabah secara langsung sebagai sarana pemasaran jasa perbankan. Perusahaan perbankan masing masing berusaha memberikan pelayanan kepada nasabah dengan baik dan memberikan informasi layanan yang terbaru tentang produk jasa yang dimiliki perusahaan, supaya para pelanggan atau nasabah dapat tetap menggunakan jasa perbankan.
Perbankan memerlukan menjalin hubungan kepada nasabah atau pun calon nasabah secara jangka panjang dengan melalui program Relationship Marketing.Relationship Marketing adalah proses penciptaan, pemeliharaan dan pengusutan hubungan yang kuat dan penuh nilai dengan pelanggan dan pemercaya lainnya (Kotler dan Amstrong, 2003: 302).Relationship Marketing biasanya lebih sering digunakan dalam perusahaan jasa, dilihat dari segi pelanggan, kebanyakan para pelanggan memerlukan pelayanan jasa yang tinggi, sehingga dalam konsep Relationship Marketing, pemasar sangat menekankan pentingnya hubungan baik jangka panjang dengan pelanggan dan infrastruktur pemasaran,dalam hal ini yang perlu diperhatikan dalam Relationship Marketing adalah mendengar dan melihat informasi dari pelanggan serta calon pelanggan yang dapat di lihat pada Customer Value (nilai pelanggan) yang akan digunakan oleh perusahaan sebagai acuan untuk meningkatkan kualitas layanan jasa yang ada di perusahaan tersebut.

Customer Value (nilai pelanggan) adalah ikatan emosional yang terjalin antara pelanggan dan produsen setelah pelanggan menggunakan produk dan jasa dari perusahaan dan mendapati bahwa produk atau jasa tersebut memberi nilai tambah (Hurriyati 2005: 296-297). Nilai pelanggan melibatkan kondisi secara penuh untuk mendapatkan informasi pelanggan serta calon pelanggan guna meningkatkan kualitas layanan dengan harapan pelanggan dapat tetap menggunakan jasa pada perusahaan.

1 Penulis Korespondensi 
Customer Loyalty (loyalitas pelanggan) adalah sebuah sikap yang menjadi dorongan perilaku untuk melakukan pembelian produk/jasa dari suatu perusahaan yang menyertakan aspek perasaan didalamnya, khusunya yang membeli secara teratur dan berulang-ulang dengan konsistensi yang tinggi, namun tidak hanya membeli ulang suatu barang dan jasa, tetapi juga mempunyai komitmen dan sikap yang positif terhadap perusahaan yang menawarkan produk/ jasa tersebut. Setiap perusahaan pada umummnya menginginkan pelanggan yang diciptakannya dapat dipertahankan selamanya, karena pelanggan yang loyal adalah asset terbesar suatu perusahaan yang harus dijaga oleh perusahaan.

Bank Jatim adalah sebuah Badan Usaha Milik Daerah (BUMD) di Provinsi Jawa Timur. Bank ini didirikan pada tanggal 17 Agustus 1961 dengan bentuk perseroan terbatas (PT), kemudian dalam perkembangannya berubah status menjadi Badan Usaha Milik Daerah (BUMD).Penanganan nasabah Bank Jatim telah meraih Award indeks loyalitas nasabah pada IBLI 2014 dengan peringkat kedua setelah Bank Jateng. Bank jatim mendapatkan penghargaan terhadap loyalitas nasabah, maka sistem penanganan nasabah seperti pelayanan kepada nasabah, menghadapi nasabah serta kesopanan kepada nasabah Bank Jatim memiliki tingkat yang baik, selain itu bank jatim juga mendapatkan peringkat keempat Best Banking Service Excellence di tahun 2014 yang di selenggarakan oleh Marketing Research Indonesia. Bank Jatim semakin mantap dalam melangkah guna memberikan yang terbaik dimasa yang akan datang. Dengan dorongan perekonomian dan meningkatkan taraf hidup rakyat, maka didirikan cabang - cabang PT. Bank Jatim di beberapa kota. Berdasarkan hal tersebut, maka pada tanggal 1 Juli tahun 1974 didirikan PT. Bank Jatim Cabang Jember dengan izin usaha No. Kep. 269/DMJ/III 3/ 5/ 1974. Pada saat awal berdirinya Bank Jatim, pendirian kantor PT. Bank Jatim Cabang Jember bergabung dengan kantor Pemerintah Daerah Tingkat II sampai tahun 1990 dan pada tahun 1991 menempati kantor sendiri di jalan PB. Sudirman no. $41-43$ Jember dan berpindah tempat mulai tanggal 13 September 2005 mulai menempati gedung baru di jala Ahmad Yani No. 3A Jember. Penelitian ini memfokuskan pada implementasi proses Customer Relationship Marketing pada perusahaan perbankan, karena perbankan merupakan salah satu penyedia jasa yang menerapkan adanya keramahtamahan dalam hubungan dengan pelanggan, maka diperlukannya strategi untuk mempertahankan pelanggan agar tidak berpindah kepada bank lain.

Nasabah menilai penggunaan jasa pada bank sesuai dengan harapan mereka atas jasa tersebut. Customer Relationship Marketing dapat menciptakan Customer Loyalty yang diinginkan perusahaan. Penelitian ini sejalan dengan penelitian yang telah dilakukan oleh Diah (2016) dimana pengaruh Customer Relationship Marketing memiliki pengaruh yang signifikan terhadap Customer Loyalty. Berdasarkan penjelasan tersebut dapat diperoleh hipotesis pertama dalam penelitian ini yaitu Customer Relationship Marketing berpengaruh signifikan terhadap Customer Loyalty (H1).

Loyal atau tidaknya seorang nasabah ditunjukan pada saat nasabah mengkonsumsi jasa yang disediakan, merasakan manfaat dari jasa yang digunakan dan merasakan pelayanan.
Apabila nasabah merasa jasa yang mereka gunakan sesuai dengan harapan mereka, maka nasabah tersebut akan memunculkan sebuah nilai yang dimana nilai tersebut akan menimbulkan rasa loyal kepada perusahaan. Penelitian yang telah dilakukan oleh Didik Isnadi (2015) dimana pengaruh Customer Relationship Marketing memiliki pengaruh yang signifikan terhadap Customer Value. Berdasarkan penjelasan tersebut dapat diperoleh hipotesis yaitu Customer Relationship Marketing berpengaruh signifikan terhadap Customer Value (H2).

Nilai pelanggan juga dapat mempengaruhi dari pengunaan jasa, dimana nasabah yang memilki nilai positif akan mempertahankan dirinya untuk menggunakan jasa tersebut dan secara keseluruhan akan menjadi loyal. Dimana nasabah yang loyal tersebut akan mempromosikan atau memperkenalkan jasa yang telah mereka rasakan kepada calon nasabah lain. Dalam penelitian yang dilakukan oleh Didik (2015) dimana pengaruh Customer Value memiliki pengaruh yang signifikan terhadap Customer Loyalty. Berdasarkan penjelasan tersebut dapat diperoleh hipotesis yaitu Customer Value berpengaruh signifikan terhadap Customer Loyalty (H3).

Artikel ini bertujuan untuk (a) menganalisis pengaruh Customer Customer Relationship Marketing terhadap Customer Value pada Bank Jatim di Jember, (b) menganalisis pengaruh Customer Customer Relationship Marketing terhadap Customer Loyalty pada Bank Jatim di Jember, (c) menganalisis pengaruh Customer Value terhadap Customer Loyalty pada Bank Jatim di Jember.

\section{Metode}

\section{Rancangan atau Desain Penelitian}

Artikel ini menggunakan penelitian Explanatory Research yaitu penelitian yang menjelaskan hubungan kausal dan menguji keterkaitan antara beberapa variabel melalui pengujian hipotesis atau penelitian penjelasan (Singarimbun dan Effendi, 1995:5).

\section{Jenis dan Sumber Data}

Jenis data yang digunakan dalam artikel ini adalah data kuantitatif. Sumber data yang digunakan adalah data primer yang diperoleh dari penelitan.

\section{Populasi dan Sampel}

Populasi dalam artikel ini adalah seluruh nasabah Bank Jatim Jember. Sample dalam artikel ini adalah 110 responden dengan kriteria nasabah yang telah menggunakan jasa pada Bank Jatim selama 2 tahun.

\section{Metode Analisis Data}

Metode analisis data yang digunkan dalam artikel ini adalah metode analisis jalur (Path Analysis) untuk menganalisis pengaruh dari Customer Relationship Marketing terhadap Customer Loyalty, Customer Relationship Marketing terhadap Customer Value, Customer Value terhadap Customer Loyalty pada Bank Jatim Jember.

\section{Hasil dan Pembahasan}

\section{Data Penelitian}

Berikut adalah hasil dari deskripsi statistik variabel Customer 
Relationship Marketing, Customer Value, Customer Loyalty pada Tabel 1.

Tabel 1. Hasil Analisis Deskripsi Statistik Variabel Customer Relationship Marketing (X), Customer Value (Z) dan Customer Loyalty (Y)

\begin{tabular}{ccccccc}
\hline Item & \multicolumn{5}{c}{ Rata - Rata Jawaban Responden \% } \\
\cline { 2 - 7 } Variabel & SS & S & CS & TS & STS & Total \% \\
\hline X & 27,3 & 36,8 & 26,8 & 8,2 & 0,9 & 100 \\
\hline Y & 20,6 & 33,6 & 35,4 & 9,4 & 0,9 & 100 \\
\hline Z & 16,5 & 39,8 & 34,5 & 21,6 & 0 & 100 \\
\hline
\end{tabular}

Sumber : Data Primer diolah, 2016

Tabel 1 menunjukan bahwa nasabah setuju dengan adanya strategi Customer Relationship Marketing yang digunakan oleh pihak Bank Jatim Jember. Nasabah juga cukup setuju jika Customer Value menentukan nasabah untuk loyal atau tidaknya kepada Bank Jatim Jember.

\section{Hasil Analisis Data}

Berikut adalah hasil analisis jalur.

Tabel 2. Hasil Rekapitulasi Analisis Jalur

\begin{tabular}{cccccc}
\hline \multicolumn{2}{c}{ Unstandarized } & \multirow{2}{*}{ thitung } & & \multirow{2}{*}{$\mathrm{t}$ tabel } & \multirow{2}{*}{ Keterangan } \\
\cline { 1 - 4 } Jalur & $\mathrm{B}$ & & & & \\
$\mathrm{X} \rightarrow \mathrm{Z}$ & 0,36 & 5,03 & $>$ & 1,66 & Signifikan \\
\hline $\mathrm{X} \rightarrow \mathrm{Y}$ & 0,35 & 5,86 & $>$ & 1,66 & Signifikan \\
\hline $\mathrm{Z} \rightarrow \mathrm{Y}$ & 0,42 & 5,66 & $>$ & 1,66 & Signifikan \\
\hline
\end{tabular}

Sumber : Data primer diolah, 2016

Tabel 2 menunjukan bahwa dari hasil tersebut menunjukan dari masing - masing variabel berpengaruh secara signifikan terhadap Customer Loyalty.

\section{Pembahasan}

a. Pengaruh Customer Relationship Marketing terhadap Customer Loyalty (H1)

Artikel ini menunjukkan bahwa Customer Relationship Marketing yang dilakukan oleh Bank Jatim membuktikan bahwa program yang dilakukan dengan memberikan pelayanan sesuai dengan keinginan nasabah, maka nasabah dapat mempersepsikan bahwa pelayanan Bank Jatim memberikan fasilitas kenyamanan kepada nasabah untuk dapat memberikan kesan yang menarik kepada nasabah, serta membangun pengalaman kemitraan nasabah dengan program promosi yang telah ditawarkan oleh Bank Jatim dari sebuah produk jasa yang ditawarkan nasabah dapat menikmati kemudahan dalam bertransaksi di Bank Jatim. Nasabah akan merasa nyaman menggunakan produk jasa yang ditawarkan oleh Bank Jatim dan menumbuhkan rasa semakin loyal pada nasabah tersebut ketika produk jasa yang di tawarkan oleh Bank Jatim sesuai dan lebih inovatif.

Hasil pengujian yang dilakukan dalam artikel ini menunjukan bahwa H1 Customer Relationship Marketing berpengaruh signifikan terhadap Customer Loyalty pada Bank Jatim Jember. Hasil tersebut membuktikan bahwa hipotesis tersebut sesuai.

b. Pengaruh Customer Relationship Marketing terhadap Customer Value (H2)
Artikel ini menunjukan bahwa Customer Relationship Marketing yang dilakukan Bank Jatim memberikan dampak positif, sehingga nasabah merasa senang dengan pelayanan yang telah diberikan Bank Jatim. Karyawan Bank Jatim memberikan informasi seputar produk jasa kepada nasabah dengan jelas hal ini salah satu upaya Bank Jatim untuk membentuk suatu nilai yang akan membuat nasabah itu merasakan kinerja yang dilakukan oleh Bank Jatim sesuai dengan harapan mereka. Dengan keramah tamahan dari para karyawan Bank Jatim dapat menimbulkan kesan yang baik serta menarik terhadap nasabah. Bank Jatim juga memberikan suku bunga bersaing kepada nasabah diamana suku bunga ini yang membuat nasabah tertarik untuk melakukan kredit di Bank Jatim, dengan adanya suku bunga bersaing ini para nasabah dapat membandingkan bank mana yang memilki suku bunga yang sesuai dengan harapan nasabah

Hasil pengujian yang dilakukan dalam artikel ini menunjukan bahwa H2 Customer Relationship Marketing berpengaruh signifikan terhadap Customer Value pada Bank Jatim Jember. Hasil tersebut membuktikan bahwa hipotesis tersebut sesuai.

c. Pengaruh Customer Value terhadap Customer Loyalty (H3) Artikel ini menunjukan bahwa Customer Value yang dimiliki oleh Bank Jatim membuktikan terbentuknya suatu nilai tersebut dengan ditawarkannya program yang ada serta pelayanan yang baik kepada nasabah. Mereka dapat menentukan program atau tawaran apa yang diberikan oleh Bank Jatim, mulai dari tabungan sampai dengan kredit yang ditawarkan tentunya akan memberikan rasa dan jaminan yang sesuai bagi mereka. Bank Jatim juga memberikan sebuah jaminan keamanan kepada nasabah yang memilih untuk produk tabungan. Para nasabah akan beranggapan bahwa layanan dan produk jasa yang mereka gunakan akan memiliki rasa keamanan dan kenyamanan. Nilai yang diperoleh nasabah dari pemakaian atau merasakan suatu pelayanan yang diberikan Bank Jatim tersebut akan menumbuhkan rasa loyal terhadap perusahaan.

Hasil pengujian yang dilakukan dalam artikel ini menunjukan bahwa H3 Customer Value berpengaruh signifikan terhadap Customer Loyalty pada Bank Jatim Jember. Hasil tersebut membuktikan bahwa hipotesis tersebut sesuai.

\section{Simpulan}

\section{Kesimpulan}

Artikel ini memberikan penjelasan bahwa Customer Relationship Marketing berpengaruh secara signifikan terhadap Customer Loyalty, Customer Relationship Marketing berpengaruh secara signifikan terhadap Customer Value dan Customer Value berpengaruh secara signifikan terhadap Customer Loyalty.

\section{Keterbatasan}

Keterbatasan dalam artikel ini adalah Pertama, perlu dipandunya responden untuk mengisi kuesioner, ada beberapa responden memerlukan panduan untuk mengisi kuesioner. Kedua, kesulitan untuk melakukan perijinan pada Bank Jatim Jember, dikarenakan perijinan dari pihak Bank Jatim Jember, maka peneliti mengambil data Bank Jatim Jember pada Bank Jatim Pusat. 


\section{Ucapan Terima Kasih}

Penulis mengucapkan terima kasih kepada pihak yang telah membantu untuk kesempurnaan artikel ini, terima kasih kepada para responden yang telah berkenan meluangkan waktunya untuk mengisi kuesioner, dan terima kasih kepada pihak Bank Jatim selaku tempat objek penelitian baik dari pihak penyedia data, maupun pihak yang telah memberikan masukan pada artikel ini.

\section{Referensi}

Diah, Yulisetiarini. 2016. The Effect of Relationship Marketing Towards Customer Satisfaction and Customer Loyalty on Franchised Retails in East Java. Mediterranean Journal of Social Sciences MCSER Publishing, Rome-Italy. Vol. 7 No. 1.

http://www.mcser.org/journal/index.php/mjss/article/viewFile/8680/8338

Didik, Isnadi. 2005. Analisis Pengaruh Customer Customer Relationship Marketing terhadap Nilai Nasabah dan Keunggulan produk Dalam Meningkatkan Kepuasan dan Loyalitas Nasabah. Tesis. Semarang : Universitas Diponegoro.

Hurriyati, Ratih. 2005. Bauran Pemasaran dan Loyalitas Pelanggan. Bandung: Alfabeta.

Kotler, Philip dan Gary Amstrong. 2003. Dasar-dasar Manajemen Pemasaran. Jilid 1. Jakarta: PT. Prehalindo. 